\title{
Outcome of bilateral adrenalectomy in congenital adrenal hyperplasia: one unit's experience
}

\author{
Cara Megan Ogilvie ${ }^{1}$, Gill Rumsby ${ }^{2}$, Tom Kurzawinski ${ }^{3}$ and Gerard S Conway ${ }^{1}$ \\ Departments of ${ }^{1}$ Endocrinology, ${ }^{2}$ Clinical Biochemistry and ${ }^{3}$ Surgery, University College London Hospitals, London, UK
}

(Correspondence should be addressed to G Conway, Department of Endocrinology, UCLH Foundation Trust, 250 Easton Rd, London NW1 2PQ, UK; Email: g.conway@ucl.ac.uk)

\begin{abstract}
Objective: The use of bilateral adrenalectomy in the management of congenital adrenal hyperplasia $(\mathrm{CAH})$ is controversial. We set out to review the outcome of 5 cases of $\mathrm{CAH}$ who have undergone adrenalectomy in our unit.

Design: A retrospective case note review and subject interview of the experience of adrenalectomy in the setting of a tertiary adult CAH clinic.

Methods: Subjects who had undergone adrenalectomy were reviewed at a routine clinic visit with particular reference to clinical and biochemical outcomes after adrenalectomy.

Results: Two subjects underwent surgery for the sole indication of desire for fertility with successful outcome and without subsequent adrenal crises. Three women suffered from the common clinical management problem of unsuppressible hyperandrogenism and worsening obesity. Whilst the outcome of improved appearance and weight loss was achieved in these subjects, all three experienced significant complications including pigmentation and acute episodes of adrenal insufficiency.

Conclusion: We present a mean follow-up of 4.2 patient years and conclude that this procedure may be suitable for selected women with CAH. Outcomes for those pursuing fertility were positive; however, complications were noted in those women for whom the procedure was performed for symptom control. Accepting that the number of subjects is small, it is clear that more data are required before widely recommending this procedure.
\end{abstract}

European Journal of Endocrinology 154 405-408

\section{Introduction}

Medical management of congenital adrenal hyperplasia (CAH) often fails to achieve an optimal outcome, particularly with regard to fertility and obesity (1). Bilateral adrenalectomy is still little explored as a treatment for $\mathrm{CAH}$. A handful of cases have been published in the literature, and these have been reviewed (2). Thirteen of these were 16 years of age or less at adrenalectomy (2). There are less data available for adults $(2-4)$.

\section{Materials and methods}

\section{Patients}

We present five subjects with CAH who have undergone bilateral adrenalectomy with particular reference to the indication for surgery and the complications of the procedure.

\section{Methods}

In the adult $\mathrm{CAH}$ clinic at the Middlesex Hospital, London, 114 individuals with 21-hydroxylase deficiency have been followed of whom five have undergone adrenalectomy. A summary of their key features is presented in Table 1. Two women underwent the procedure to achieve fertility. Over this same time period, 12 of the 44 women with salt wasting $\mathrm{CAH}$ in this cohort tried to conceive. Five achieved spontaneous pregnancy, four required clomiphene and/or low dose gonadotrophin ovulation induction, and two underwent adrenalectomy. One woman has not achieved a pregnancy.

Three women had the clinical conundrum of difficult hyperandrogenism and progressive obesity. The overall clinic data for body mass index (BMI) is represented in Fig. 1. The BMI for these three women were in the upper range of the cohort and they were very symptomatic from their non-suppressible androgen levels.

\section{Results}

\section{Bilateral adrenalectomy for fertility}

Case 1 A 31-year-old woman was referred with three years of primary infertility. She presented at birth with clitoromegaly, labial fusion (Prader stage 11), 
Table 1 A summary of each case considering genotype, indications for and complications of procedure.

\begin{tabular}{|c|c|c|c|c|c|c|c|}
\hline Indication & Case & $\begin{array}{l}\text { Age at } \\
\text { surgery } \\
\text { (years) }\end{array}$ & Genotype & $\begin{array}{l}\text { HC }(\mathrm{mg}) \text { equiv } \\
\text { pre/post }\end{array}$ & $\begin{array}{l}\text { Fludro }(\mu \mathrm{g}) \\
\text { pre/post }\end{array}$ & $\begin{array}{l}\text { Post operative } \\
\text { complications }\end{array}$ & $\begin{array}{c}\text { Follow-up period } \\
\text { (years) }\end{array}$ \\
\hline \multirow[t]{2}{*}{ Fertillity } & 1 & 34 & $\begin{array}{l}\text { Deletion/172N } \\
\text { Salt wasting }\end{array}$ & $35 / 15$ & $200 / 150$ & Nil & 3 \\
\hline & 2 & 37 & $\begin{array}{l}172 N / 318 \times \\
\text { Salt wasting }\end{array}$ & $40 / 30$ & $200 / 100$ & Nil & 6 \\
\hline \multirow[t]{3}{*}{$\begin{array}{l}\text { Obesity/ } \\
\text { virilisation }\end{array}$} & 3 & 34 & $\begin{array}{l}\text { 172N/CL6-281L } \\
\text { Salt wasting }\end{array}$ & $25 / 20$ & $200 / 100$ & $\begin{array}{l}\text { Hyperpigmentation with } \\
\uparrow \uparrow A C T H \text { Adrenal crisis } \times 1\end{array}$ & 6 \\
\hline & 4 & 15 & $\begin{array}{l}\text { IVS2-13G/deletion } \\
\text { Salt wasting }\end{array}$ & $40 / 30$ & $300 / 300$ & $\begin{array}{l}\text { Hyperpigmentation with } \\
\uparrow \uparrow \text { ACTH Adrenal crisis } \times 1\end{array}$ & 4 \\
\hline & 5 & 21 & $\begin{array}{l}\text { Deletion/deletion } \\
\text { Salt wasting }\end{array}$ & $37.5 / 35$ & $150 / 300$ & $\begin{array}{l}\text { Hyperpigmentation Adrenal } \\
\text { crises } \times 3\end{array}$ & 2 \\
\hline Mean value & & & & $35.5 / 26$ & $210 / 190$ & & 4.2 \\
\hline
\end{tabular}

$\mathrm{HC}$, hydrocortisone equivalents, dexamethasone: 80:1, prednisolone 5:1; Fludro, fludrocortisone; $\uparrow \uparrow \mathrm{ACTH}$, extreme elevation in ACTH (>20 times the upper limit of the normal range).

and salt wasting. Menarche occurred at 16 years of age. Dexamethasone was used, as was standard treatment for the time, but her weight increased throughout her young adult life. Initial fertility $\times$ attempts using clomiphene citrate had successfully induced ovulation.

Her BMI was $31 \mathrm{~kg} / \mathrm{m}^{2}$ and a random serum 17-hydroxyprogesterone (170HP) value was $0.79 \mathrm{ng} / \mathrm{ml}(2.6 \mathrm{nmol} / \mathrm{l}$ (normal range $0-6))$. A pelvic ultrasound scan demonstrated polycystic ovaries, fallopian tubes were patent. Ovulation tracking of a spontaneous cycle using ultrasound showed ovarian activity with dominant follicles of $18 \mathrm{~mm}$. Luteal phase progesterone concentrations were in the range of $5-10 \mathrm{ng} / \mathrm{ml}(17-32 \mathrm{nmol} / \mathrm{l})$, but follicular phase progesterone was raised at $2.8 \mathrm{ng} / \mathrm{ml}(8.8 \mathrm{nmol} / \mathrm{l})$ at a time when $17 \mathrm{OHP}$ was suppressed at $0.88 \mathrm{ng} / \mathrm{ml}$ $(2.9 \mathrm{nmol} / \mathrm{l})$. Increasing doses of prednisolone and fludrocortisone failed to suppress follicular phase progesterone and this was considered to be the main cause of infertility, resulting in inadequate thickening of the endometrium.

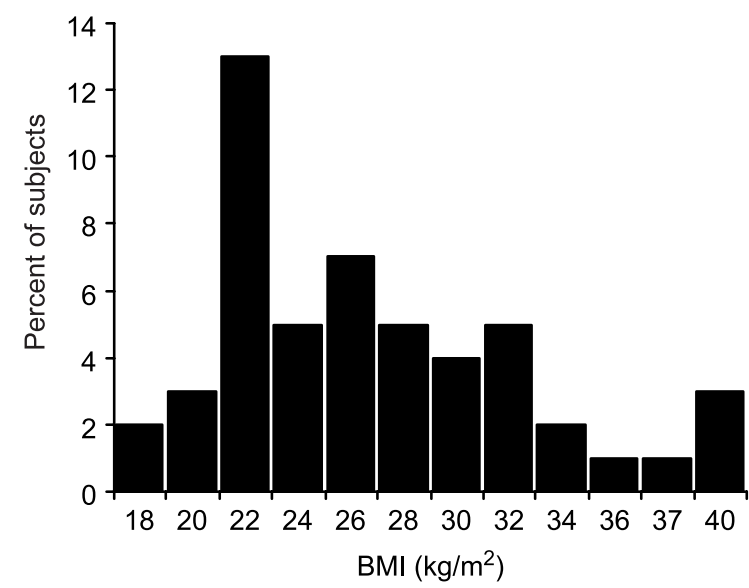

Figure 1 Body mass index range within the Middlesex cohort of people with $\mathrm{CAH}$.
Laparoscopic bilateral adrenalectomy was undertaken. The right adrenal gland weighed $11 \mathrm{~g}$ and the left gland $6 \mathrm{~g}$ (normal, non CAH adrenal gland 3-5 g) (5). Normal menstrual cycles resumed, accompanied by weight loss (Fig. 2).

Follicular phase progesterone was recorded as $0.7 \mathrm{ng} / \mathrm{ml} \quad(0.6 \mathrm{nmol} / \mathrm{l})$. Pregnancy occurred spontaneously, and a healthy male baby was delivered by Caesarean section 26 months after adrenalectomy.

Case 2 A 33-year-old woman was referred with twelve years of primary infertility. Her case has been published previously as the first case of progesterone hypersecretion in the follicular phase of the cycle in our unit (6). Briefly, she presented at 3 weeks with classical features of CAH. Follicular phase progesterone was not suppressible by medical means and she underwent bilateral open adrenalectomy. The left adrenal weighed $26 \mathrm{~g}$ (it contained an adenoma) and the right adrenal weighed $7.5 \mathrm{~g}$. Post-operatively, her weight fell by $7 \mathrm{~kg}$ and she subsequently had two separate spontaneous pregnancies.

\section{Bilateral adrenalectomy for progressive obesity and virilisation}

Case 3 A 21-year-old woman was referred after paediatric transition. She had presented at 9 days old with labial fusion, clitoromegaly (Prader stage 11), pigmentation and salt wasting. Menarche occurred at 20 years of age. Her BMI was $41 \mathrm{~kg} / \mathrm{m}^{2}$ and a pelvic ultrasound scan showed polycystic ovaries.

Management issues included obesity and hyperandrogenism with virilisation. Various forms of androgen suppression had been used including the combined oral contraceptive pill, gonadotrophin-releasing hormone analogue, cyproterone acetate and flutamide. An open bilateral adrenalectomy was performed at 34 years of age. The left adrenal weighed $25.4 \mathrm{~g}$ and the right $42 \mathrm{~g}$. Post-operative testosterone concentrations were below 


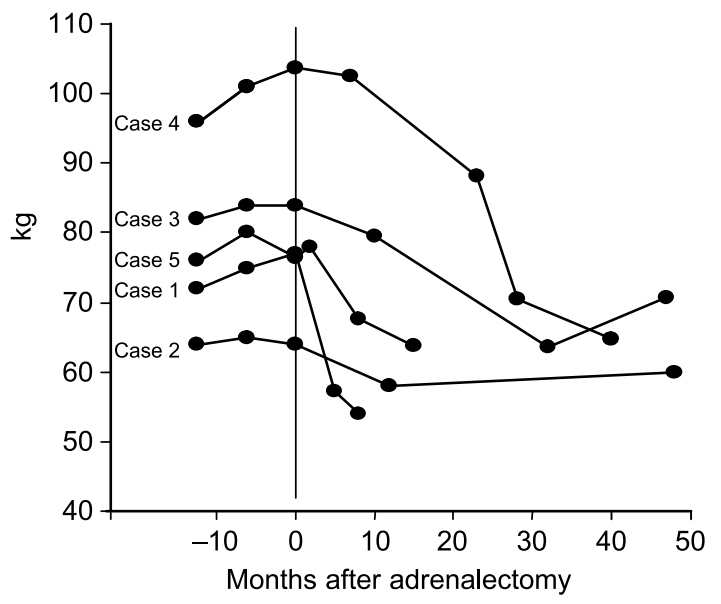

Figure 2 Weight change after adrenalectomy in five women with $\mathrm{CAH}$. Degree of weight loss for each case after bilateral adrenalectomy. The vertical line on the graph indicates timing of surgery.

the limit of detection of the assay. The patient has had variable pigmentation following surgery and an increasing plasma adrenocorticotrophin (ACTH) concentration up to $>1250 \mathrm{ng} / \mathrm{l}(<46)$. One adrenal crisis occurred which was precipitated by a viral illness.

Case 4 A female baby presented at birth with ambiguous genitalia (Prader stage 1) and salt wasting. Throughout childhood her weight remained on the $90^{\text {th }}$ centile. At 14 years of age, acne and weight were uncontrolled. At 15 years of age, her BMI was $38 \mathrm{~kg} / \mathrm{m}^{2}$ with significant virilisation with hirsutism, voice deepening and acne, and elevated serum androgens.

Laparoscopic bilateral adrenalectomy was performed. Acne improved but pigmentation became significant and ACTH peaked at $4340 \mathrm{ng} / \mathrm{l}$ (normal <46). A normal magnetic resonance imaging scan of the pituitary ruled out Nelson's Syndrome. Spontaneous regular menstruation started at 17 years of age. An abdominoplasty was performed after a weight loss of $22 \mathrm{~kg}$. An adrenal crisis occurred, the details of which were not forwarded from the secondary centre involved.

Case 5 A baby presented at birth with ambiguous genitalia and clitoromegaly (Prader stage 11). Early childhood was complicated by frequent hypoglycaemic episodes that were resolved after conversion from hydrocortisone to prednisolone. This change was associated with slowing of growth velocity and at 7 years of age hydrocortisone was reinstated. The family was lost to follow-up but re-presented at 16 years of age. Intermittent compliance had led to severe hirsutism and deepening of the voice. Menarche occurred at18 years of age but only 3 periods eventuated. A pelvic ultrasound scan showed polycystic ovaries. Testosterone and androstenedione concentrations remained elevated and she became increasingly overweight (BMI $31 \mathrm{~kg} / \mathrm{m}^{2}$ ), virilised and intolerant of antiandrogens.

Laparoscopic bilateral adrenalectomy was performed, the left adrenal gland weighed $46 \mathrm{~g}$ and the right gland 41 g. Spontaneous menstruation resumed postoperatively and her BMI decreased to $22 \mathrm{~kg} / \mathrm{m}^{2}$ (Fig. 2). Profound generalised pigmentation occurred and in the year after surgery she had 3 acute admissions with acute adrenal insufficiency that appeared to have no precipitating factor and may have been related to a higher than expected requirement for fludrocortisone post adrenalectomy ( $300 \mu \mathrm{g}$ per day) and a degree of non-compliance (7).

\section{Discussion}

We present the outcomes of bilateral adrenalectomy in 5 women with $\mathrm{CAH}$ in whom there were two main indications for surgery: infertility or the combination of obesity and virilisation. This is the largest such series to be presented from a single centre. Nevertheless, the series is small and conclusions must be tentative.

The outcome of surgery in all five cases was positive with respect to weight loss and fall in circulating androgen concentrations. The mean dose of glucocorticoid was reduced from $35.5 \mathrm{mg}$ hydrocortisone equivalence to $26 \mathrm{mg}$ and the mean dose of fludrocortisone changed only slightly (Table 1).

The two patients who were pursuing fertility had particularly good outcomes. Pregnancies occurred spontaneously within two years; in case 2 this was after 12 years of investigation and treatment of primary infertility. Neither woman experienced subsequent adrenal insufficiency or pigmentation.

Follicular phase progesterone remained elevated despite good suppression of androgens and 170HP. A subgroup of women with $\mathrm{CAH}$ and elevated follicular phase progesterone has been described previously (6). The raised progesterone most likely arises from deficient 21-hydroxylation of progesterone in the zona glomerulosa, which may act to suppress fertility by persistent inhibition of follicular growth, poor endometrial thickening and impermeability of the cervical mucus (8). Why some but not all women with $\mathrm{CAH}$ exhibit this phenomenon is unclear. Premawardhana and colleagues (1) reported the common observation that elevated follicular progesterone could be associated with poor $\mathrm{CAH}$ control. Others have demonstrated that good suppression of both androgen and 170HP levels do not always prevent elevation of follicular phase progesterone $(6,9)$.

For the three women for whom the indication for surgery was obesity and virilisation, the overall outcome was mixed. While all experienced weight loss and regular menstruation, these benefits have to be balanced against universal pigmentation and acute admissions for adrenal crises. Notably, this group had 
marked adrenal hyperplasia suggesting poor compliance preoperatively, which, in retrospect, was likely to continue postoperatively and therefore provides some explanation for the adrenal crises seen in this group.

In a review of the 18 published cases of adrenalectomy in CAH, hyperpigmentation was observed in more than half (2). Pigmentation was responsive to elevations in glucocorticoid replacement and it is possible this particular complication is a result not only of poor compliance with medical treatment but also of a learned psychological response to obesity leading to reduction in glucocorticoid compliance as a tool to accelerate weight loss. Previous series (2) have presented a third indication for bilateral adrenalectomy - a prophylactic therapy for those children with severe mutations indicating high probability of severe $\mathrm{CAH}$. If the procedure is performed as a young child it seems possible that the complication of hyperpigmentation may not occur as such learned behaviours of compliance have not developed. Such noncompliance that may explain the very high ACTH levels seen in patients 3 and 5 (and possibly some of the weight loss) is concerning and indicates the need for strict follow-up and particular emphasis on stress-related glucocorticoid dose adjustment. The danger of adrenal crises cannot be overemphasised, especially in children and adolescents.

All the above-mentioned women underwent surgery prior to relevant data regarding assessment of catecholamine status being published $(10,11)$. While the clinical relevance of catecholamine deficiency in $\mathrm{CAH}$ is uncertain, from the little data available it seems likely that those who have undergone adrenalectomy have even lower circulating catecholamines than those with intact adrenals and this change may affect management post surgery.

\section{Conclusion}

In summary, we present five cases of bilateral adrenalectomy for congenital adrenal hyperplasia from one unit. Two operations were performed to allow fertility and both were successful. Accepting that our numbers are small, our experience has led us to be positive about this procedure in cases where fertility is desired especially if elevation of progesterone in the follicular phase is demonstrated.

We would be cautious of recommending this procedure in adult cases of difficult to control obesity and hyperandrogenism. Complications included adrenal crises and increased skin pigmentation, compounded by reluctance to increase glucocorticoid replacement due to fear of weight gain. It must be noted that in a previous series (1) only one of the eight subjects having the procedure for the same indication suffered from an adrenal crisis. In the same series, seven out of the nine subjects less than 14 years of age did not have any crises, although in these cases there is presumably a parental control factor that may be important. In all our cases, however, positive results in terms of weight control and better biochemical profiles were recorded. Compliance with therapy, both pre and post operatively is obviously vital. Outcomes in this second group may have been more positive if demonstrated compliance had been a pre-operative requirement.

\section{References}

1 Premawardhana LD, Hughes IA, Read GF \& Scanlon MF. Longer term outcome in females with congenital adrenal hyperplasia: the Cardiff experience. Clinical Endocrinology 199746 327-332.

2 Van Wyk JJ \& Ritzen EM. The role of bilateral adrenalectomy in the treatment of congenital adrenal hyperplasia. Journal of Clinical Endocrinology and Metabolism $2003 \mathbf{8 8}$ 2993-2998.

3 Gmyrek GA, New MI, Sosa RE \& Poppas DP. Bilateral laparoscopic adrenalectomy as a treatment for classic congenital adrenal hyperplasia attributable to 21-hydroxylase deficiency. Pediatrics 2002109 E28.

4 Warriner SA, Zimmerman D, Thompson GB \& Grant CS. Study of three patients with congenital adrenal hyperplasia treated by bilateral adrenalectomy. World Journal of Surgery 200024 1347-1352.

5 Bourne GH. In The Adrenal Cortex, p 20. Ed. HD Moon. New York: Paul B Hoeber, 1961.

6 Holmes-Walker DJ, Conway GS, Honour JW, Rumsby G \& Jacobs HJ. Menstrual disturbance and hypersecretion of progesterone in women with congenital adrenal hyperplasia due to 21-hydroxylase deficiency. Clinical Endocrinology $1995 \quad \mathbf{4 3}$ 291-296.

7 Merke DM \& Camacho CA. Novel basic and clinical aspects of congenital adrenal hyperplasia. Reviews in Endocrine and Metabolic Disorders 20012 289-296.

8 Stikkelbroeck NM, Hermus RM, Braat DD \& Otten B. Fertility in women with congenital adrenal hyperplasia due to 21-hydroxylase deficiency. Obstetrics and Gynecology Surgery $2003 \mathbf{5 8}$ $275-284$.

9 Helleday J, Siwers B, Ritzen EM \& Carlstrom K. Subnormal androgen and elevated progesterone levels in women treated for congenital 21-hydroxylase deficiency. Journal of Clinical Endocrinology and Metabolism 199376 933-936.

10 Merke DP, Chrousos GP, Eisenhofer G, Weise M, Keil MF, Rogol AD, Van Wyk JJ \& Bornstein SR. Adrenomedullary dysplasia and hypofunction in patients with classic 21-hydroxylase deficiency. New England Journal of Medicine 2000343 1362-1368.

11 Charmandari E, Weise M, Bornstein SR, Eisenhofer G, Keil M, Chrousos GP \& Merke D. Children with classic congenital adrenal hyperplasia have elevated serum leptin concentrations and insulin resistance: potential clinical implications. Journal of Clinical Endocrinology and Metabolism $2002872114-2120$.

Received 7 September 2005

Accepted 23 November 2005 